\title{
ACTIVE SURVEILLANCE: STRATEGY TO REACH THE UNREPORTED TB PATIENT IN HOSPITALS
}

\author{
Nenden Siti Aminah, Ratna Djuwita, Paulus Daniel Sahanggamu, Soelistyo, Helmi \\ Suryani Nasution \\ ${ }^{1,3} \mathrm{KNCV}$ Tuberculosis Foundation, ${ }^{2}$ University of Indonesia, ${ }^{4,5}$ National Tuberculosis \\ Program, Ministry of Health RI \\ Email: nenden.adriyansyah@gmail.com,djuwita257@gmail.com, \\ dsahanggamu@gmail.com, sulistyopalu@yahoo.com, \\ helmi_suryani@yahoo.com
}

\begin{abstract}
Background and Aims: The National Tuberculosis Program (NTP) conducted active surveillance to find unreported TB patients in hospitals. CTB supports by conducted active surveillance in 6 provinces. This study was conducted to see an overview of the implementation of active surveillance of TB cases in hospitals among districts supported by CTB and non CTB supported, including the challenges of active surveillance implementation to provide recommendations for National TB program. Methods: This study is a qualitative research with a case study design. Data collected by document reviews, observations, discussions, and in-depth interviews with key informants. Results: Only about 23\% of TB cases from HIS are reported into SITT. This is partly due to the procedure or the flow of tuberculosis (TB) data from the Hospital to the National TB Program, which is a manually input by entry the data into the SITT.There are about $70 \%$ of cases that are not reportedly due to lack of human resources in the hospital to do data entry. Findings also show that districts supported by CTB have a percentage of cases gap less (4\%-43\%) than non CTB supported district (43\%-74\%). The data shows the importance of partnership or involvement of other partners in TB control programs. Conclusion: Active surveillance shows the need to strengthen hospital internal network. Standardized guideline and treatment monitoring mechanism should be established to support active surveillance nationwide. The NTP needs also to collaborate with the Directorate General of Health Services to establish a linkage between HIS and National TB surveillance system.
\end{abstract}

Keywords: active surveillance; national TB surveillance; hospital information system; national TB program; challenge TB

\section{Introduction}

Tuberculosis $(\mathrm{TB})$ remains a major public health problem in the world and as one of the goals in the Sustainable Development Goals (SDGs). TB is one of the top 10 causes of death and since since 2011 it has been the leading cause of death from a single infectious agent, ranking above HIV/AIDS. In Indonesia, TB control program have been

$\begin{array}{ll}\text { How to cite: } & \text { Aminah, Nenden Siti. dkk (2021) Active Surveillance: Strategy to Reach the Unreported TB Patient in } \\ & \text { Hospitals. Syntax Literate. 6(7). http://dx.doi.org/10.36418/ syntax-literate.v6i7.3465 } \\ \text { E-ISSN: } & 2548-1398 \\ \text { Published by: } & \text { Ridwan Institute }\end{array}$


implemented the DOTS strategy since 1995, however the challenge of TB control is still incredibly challenging ( $\mathrm{Li}$ et al., 2019). Indonesia is a high TB burden country, with TB as the major cause of death after ischemic heart disease and cerebrovascular disease. In 2017, WHO reported that the incidence of TB cases in Indonesia was 319 per 100,000 population or around 842,000 cases. The estimated TB mortality rate in Indonesia was 40 per 100,000 population or around 107,000 cases (excludes TB-HIV). Meanwhile the total number of cases notified in 2017 was 446,732 cases with $29 \%$ of them were TB with HIV (World Health Organization, 2018).

A national study called TB inventory Study was implemented in 2017 by National Tuberculosis Program of Indonesia. The aim of the study was to measure the level of underreporting of TB case and to identify methods for adressing TB underreporting case (Oliveira, Pinheiro, Coeli, Barreira, \& Codenotti, 2012). The inventory study found that overall level of underreporting of detected $\mathrm{TB}$ cases was $41 \%$, ranging from $15 \%$ underreporting by primary health care "puskesmas" to $65 \%$ by hospitals and $96 \%$ by general practioners (GPs). The study also reported the estimated TB cases in Indonesia are 842,000 cases, lower than previous estimation which reported more than 1 million. Nevertheless, there are still many TB patients who have not been found. Based on the Global TB Report 2018, the total TB notification in 2017 was 446,732 cases, meaning that there were around $50 \%$ of unreported yet (Ministry of Health RI, 2017).

An estimate of 450,000 TB cases reported by hospitals nationwide (HIS/SIMRS, 2017). However, the number of TB cases reported by hospitals through the national tuberculosis reporting system (SITT) is only around 100,000 cases. In 6 CTB supported provinces, around 58\% of TB notification was from hospitals and only 67,649 out of 300,382 cases reported by HIS were reported through SITT. This means only $23 \%$ of TB cases from hospitals have been reported, leaving $77 \%$ which have not been reported. Similar with the Indonesia Inventory Study which mention under reporting TB cases in hospitals were 65\% (Tola, Minshore, Ayele, \& Mekuria, 2019).

Target of TB notification in 2018 is 675,173 cases. Until July 2018 TB Notification reported through SITT (per Q2 2018) is 157,074 cases and only 9\% of cases were from hospitals. It showed that under reporting TB cases is immense. Some of the factors relate to under reporting in hospitals were not all hospitals reporting TB cases and the national TB information system has not been integrated with the Hospital Information System which cause not all cases recorded on SIMRS are reported in SITT (Danusantoso, 2000). To overcome this problem, the NTP conducted active surveillance in August-September 2018 to find unreported TB patients in hospitals, CTB supports by conducted active surveillance in 6 provinces. Ministry decree No. 67/2016 was the basis for the active surveillance. The decree stated that in conducting TB surveillance, data could be collected both with active and passive ways, either manually or electronically. In addition, NTP cooperate with partners in central level include CTB team, develop guideline as a guidance for active surveillance in hospital (Suvianto, 2020). Some research related to surveillance is more about evaluating recording and reporting or describing the quality of the existing surveillance system, for example research 
Nenden Siti Aminah, Ratna Djuwita, Paulus Daniel Sahanggamu, Soelistyo, Helmi Suryani Nasution

conducted in 2016 at the East Java Provincial Health Office. While this study was conducted to see an overview of the implementation of active surveillance of TB cases in hospitals among districts supported by CTB and non CTB supported, including the challenges active surveillance implementation to provide recommendations for National TB program.

\section{Reasearch Methods}

The Challenge TB (CTB) is a project to supports the national TB program through the implementation of a strategic plan by ensuring technical leadership. CTB project supporting TB program and working in 16 districts in 6 provinces: North Sumatra Medan City and Deli Serdang, DKI Jakarta - North Jakarta, South Jakarta, West Jakarta, Central Jakarta and East Jakarta, West Java - Bandung City and Bogor, Central Java - Semarang City and Surakarta City, East Java - Jember and Tulung Agung, Papua - Jayapura City, Jayawijaya and Mimika. Those 6 provinces have a total about 14,243 health facilities consist of 768 health centers (Puskesmas), 1,529 hospital and 11,946 GP's and clinics (The Challenge TB, 2018a).

Active surveillance was carried out on July-August 2018. In line with NTP guideline for active surveillance, CTB develop technical guideline specific for 6 CTB supported provinces to ensure active surveillance at hospitals reach the target set. The NTP and CTB at central office visit the province to share and discuss about the guideline and how to do hospital data collection. Central team together with province team visit one hospital to practice data collecting mechanism. Furthermore, each province asked to continue the hospitals visit. Hospital selected based on number of case gap reported by SIMRS and SITT, known to have a high number of cases (type A or B) and used electronic medical records. Hospitals with the most fulfilled criteria were chosen to visit. A total of 380 hospitals in 121 districts were investigated.

This study is a qualitative research with a case study design. Data collected by document reviews, observations, discussions, and in-depth interviews with key informants. Each province has a different approach in collecting data, depends on resources and situation. Before visiting the hospitals, commitment of health facilities on participating active surveillance activities gained either with audience meeting or invited to the meeting. Mechanism of data collection refers to guideline provided by NTP and CTB. In general, enumerators were recruited to assist active surveillance activities. The enumerators were trained or gave an on-the-job training by province and district team. Team consist of Senior Technical Officer (STO), Technical Officer (TO), M\&E officer (MEO), districts Data Officer (DO) and Enumerator, visit the hospitals in parallel. Data cleaning and validation done either at facility level or district level involve all team members (The Challenge TB, 2018b).

Data collected in these activities were secondary data from the hospital informastion system (HIS) and crosschecked with data from National Tuberculosis Informastion System (SITT). Before visiting hospitals there were data set should be prepared, which were data of TB Case Report 2016-2018 of district and province (TB 
03. SITT), TB Report of Hospital Information System 2017 and Template of TB.03 provided by NTP for result recap (Uddin, Wahyuni, \& Setiawan, 2021).

Data collected at hospital taken from electronic medical record of TB patients, consist of ID, name, gender, date of birth, address, date of diagnosis, classification of TB (ICD X) and name of care unit origin. Data of TB case from in patients and outpatients combined and cleaned by remove duplicate (Imas \& Nauri, 2018). To ensure period treatment of patient is the first-time patient recorded on treatment, the data were re-check with data medical record year before and after. TB patient's data which have been cleaning compared with data TB case report of SITT and SIMRS, patients registered both in SITT and SIMRS were deleted (Rahmadhani, Wijayanti, \& Nuraini, 2020). Data which not registered in SITT or SIMRS were TB case which not reported yet and should be recap to template of TB.03 provided by NTP. Treatment evaluation result will be following up on the next visit.

\section{Results and Discussion}

Data collected by enumerator sent to district data officer to be compiled. Data from district data officer compiled and analyzed by provincial ME Officer and sent to national level. The result of data analyses are as follows:

\section{Table 1}

Result of Active Surveillance in 6 CTB supported Provinces

\begin{tabular}{|c|c|c|c|c|c|c|}
\hline \multirow[t]{2}{*}{ Province } & \multicolumn{2}{|c|}{ Coverage } & \multirow{2}{*}{$\begin{array}{c}\text { Target } \\
2018\end{array}$} & \multirow{2}{*}{$\begin{array}{l}\text { TB Notification } \\
\text { Jan-Aug } 2018 \\
\text { (SITT) }\end{array}$} & \multirow[b]{2}{*}{$\begin{array}{c}\text { Additional } \\
\text { cases from } \\
\text { active } \\
\text { surveillance } \\
\text { Jan-Aug } 2018\end{array}$} & \multirow[t]{2}{*}{ Gap } \\
\hline & District & Hospital & & & & \\
\hline $\begin{array}{c}\text { North } \\
\text { Sumatera }\end{array}$ & $\begin{array}{l}16 / 33 \\
(48 \%)\end{array}$ & $\begin{array}{c}86 / 235 \\
(37 \%)\end{array}$ & 49,907 & 11,934 & 7,408 & 30,565 \\
\hline $\begin{array}{c}\text { DKI } \\
\text { Jakarta }\end{array}$ & $\begin{array}{c}5 / 6 \\
(83 \%)\end{array}$ & $\begin{array}{c}18 / 198 \\
(9 \%)\end{array}$ & 24,570 & 16,725 & 4,796 & 3,049 \\
\hline West Java & $\begin{array}{l}26 / 27 \\
(96 \%)\end{array}$ & $\begin{array}{c}56 / 359 \\
(16 \%)\end{array}$ & 106,334 & 37,634 & 16,447 & 52,253 \\
\hline $\begin{array}{c}\text { Central } \\
\text { Java }\end{array}$ & $\begin{array}{c}35 / 35 \\
(100 \%)\end{array}$ & $\begin{array}{c}131 / 303 \\
(43 \%)\end{array}$ & 70,239 & 24,275 & 21,011 & 24,953 \\
\hline East Java & $\begin{array}{l}36 / 38 \\
(95 \%)\end{array}$ & $\begin{array}{c}84 / 392 \\
(21 \%)\end{array}$ & 80,703 & 25,953 & 20,413 & 34,337 \\
\hline Papua & $\begin{array}{c}3 / 27 \\
(11 \%)\end{array}$ & $\begin{array}{c}5 / 42 \\
(12 \%)\end{array}$ & 10,271 & 4,230 & 601 & 5,440 \\
\hline Total & & & 342,024 & 120,751 & 70,676 & 150,597 \\
\hline
\end{tabular}

Source: CTB Annually Report, 2018.

As described in table 1 the number of districts visited were 121 of 166 districts. The coverage was about $73 \%$. While number of hospitals visited were 380 , coverage about $25 \%$. However, this coverage could not describe the actual magnitude, it is because most of the selected hospitals were hospitals with high TB burden, the remainder hospitals cannot reflect as an actual gap. An additional of 70,676 TB patients 
Nenden Siti Aminah, Ratna Djuwita, Paulus Daniel Sahanggamu, Soelistyo, Helmi Suryani Nasution

were found, contributed to nearly $40 \%$ of total notification. Table 4 also described that there were 150. 597 cases are still missing (Dangisso, Datiko, \& Lindtjørn, 2014).

CTB prioritize active surveillance in all districts supported by CTB and several selected districts of non CTB supported district. Comparison of data showed that districts supported by CTB have a percentage of cases gap less than non CTB supported district.

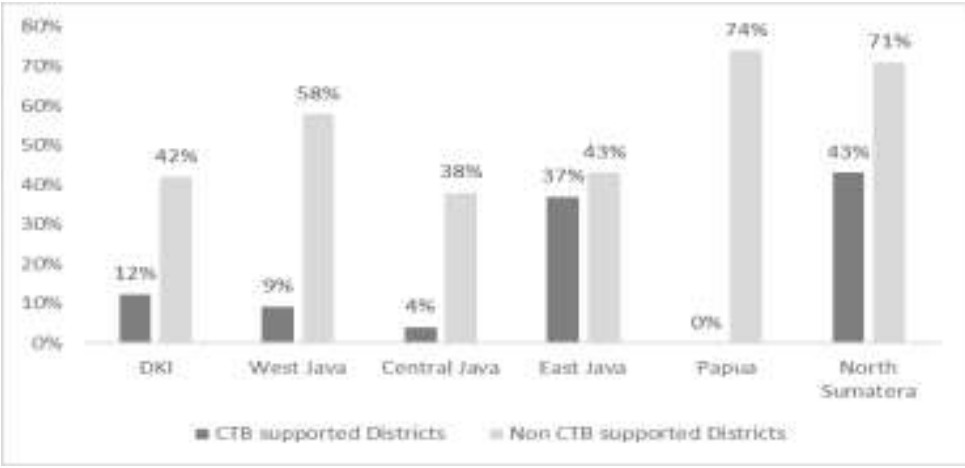

Graphics 1

Gap of Target and Case Finding TB 2018 (Routine and Active Surveillance) 6 CTB Supported Provinces

Source: CTB Annually Report, 2018.

Below is an illustration of the proportion of $\mathrm{TB}$ cases finding from active surveillance activities by type of hospitals:

Tabel 2

Proportion of Missing Case TB by Hospital Type

\begin{tabular}{clccc}
\hline No & Provinsi & \multicolumn{3}{c}{ Total Missing Case Found } \\
\cline { 3 - 5 } & $\begin{array}{c}\text { Number of } \\
\text { Missing } \\
\text { Case }\end{array}$ & $\begin{array}{c}\text { Public } \\
\text { Hospital }\end{array}$ & $\begin{array}{c}\text { Private } \\
\text { Hospital }\end{array}$ \\
\hline $\mathbf{1}$ & North Sumatera & 7408 & 3127 & 4281 \\
\hline $\mathbf{2}$ & DKI Jakarta & 4796 & 3487 & 1309 \\
\hline $\mathbf{3}$ & West Java & 16447 & 11443 & 5004 \\
\hline $\mathbf{4}$ & Central Java & 21011 & 9714 & 11297 \\
\hline $\mathbf{5}$ & East Java & 20413 & 14369 & 6044 \\
\hline $\mathbf{6}$ & Papua & 601 & 407 & 194 \\
\hline & Total & 70676 & 42547 & 28129 \\
\hline \multicolumn{2}{c}{ Proportion } & & $\mathbf{6 0 \%}$ & $\mathbf{4 0 \%}$
\end{tabular}

Source: CTB Annually Report, 2018.

Table 2 describe that the proportion of missing TB cases that were found from government hospitals in 6 CTB supported provinces was 42,547 cases from a total of 70,676 cases $(60 \%)$. While for private hospitals there were 28,129 cases from a total of 70,676 cases $(40 \%)$. 
Mentioned above that only about $23 \%$ of TB cases from HIS are reported into SITT. This is partly due to the procedure or the flow of tuberculosis (TB) data from the Hospital to the National TB Program, which is a manually input by entry the data into the SITT.There are about $70 \%$ of cases that are not reportedly due to lack of human resources in the hospital to do data entry. This is in accordance with a study under reporting of TB cases and associated fastors in China which mentioned that over a quarter of TB cases recorded in the hospital were not entered into the national TB case reporting system, leading to an under representation of national TB cases. One of the factors associated with this underreporting was unqualified and overworked health personnel (Zhou, Pender, Jiang, Mao, \& Tang, 2019).

380 hospitals were successfully visited for active surveillance activities, with 121 representing the public hospital and 239 private hospital. However, this coverage could not describe the actual magnitude, it is because most of the selected hospitals were hospitals with high TB burden, the remainder hospitals cannot reflect as an actual gap. An additional of 70,676 TB patients were found, contributed to nearly $40 \%$ of total notification. This figure left 150,597 (60\%) missing cases from the hospital. Similar finding has been reported on Indonesian inventory study conducted in 2017, mentioned that the level of underreporting of detected TB cases by Hospital was 65\%. Subsequent discussions related to capacity building and the number of human resources, integration between the HIS and SITT, reporting TB treatment regimens and coalitions of professional organizations in the PPM district base are needed to overcome under reporting problems at Hospital (Ministry of Health RI, 2017).

Our findings show that districts supported by CTB have a percentage of cases gap less (4\%-43\%) than non CTB supported district (43\%-74\%). At DKI Jakarta province, CTB supported districts have $12 \%$ of missing case gap compare to non CTB supported districts which reaches $42 \%$. West Java Province showed a similar result where the CTB supported area had a missing case gap only $9 \%$ while in non-CTB supported area the gap reached 58\%. In Central Java Province, CTB supported districts had a missing case gap only $4 \%$ while in non- CTB supported districts the gap reached $38 \%$. In the East Java province, CTB supported districts had a missing case gap $37 \%$ while in the nonCTB supported districts the gap reached 43\%. Likewise, in Papua Province, CTB supported districts did not have a missing case gap while in non- CTB supported districts the gap reached $74 \%$. Finally, the North Sumatra province also showed similar where CTB supported districts had a missing case gap $43 \%$ while in non- CTB supported districts the gap reached $71 \%$. The data shows the importance of partnership or involvement of other partners in TB control programs. Current TB control challenges have led national authorities to appreciate the contribution of the non-state sector and of civil society, and to establish effective collaborations with them. The experiences demonstrate the need for a new culture of work based on partnering and they clearly document successful attempts to work together. If this happens, working in partnership will remain an essential ingredient to achieve the future targets for TB prevention and care, and for public health (Organization, 2013). 
Nenden Siti Aminah, Ratna Djuwita, Paulus Daniel Sahanggamu, Soelistyo, Helmi Suryani Nasution

The proportion of missing cases found from public hospitals of 6 CTB supported provinces was 42,547 cases from a total of 70,676 cases $(60 \%)$, while for private hospitals there were 28,129 cases from a total of 70,676 cases $(40 \%)$. This figure is like the results of the inventory study which obtained the total number of missing cases obtained by 21,320 . From that case, those originating case from public health facilities (puskesmas and government-owned hospitals) amounted to 14,562 cases $(68 \%)$. While the number of cases originating from private health facilities (private hospitals, clinics and DPM) was 6,557 cases (31\%), the remaining 1,010 cases (5\%) were cases from the laboratory (Ministry of Health RI, 2017).

TB patients got from active surveillance should be re-checked by manual medical record, to ensure those patients actually TB patients. However not all data could be rechecked because of limted time and insufficient resources. Selected re-checked done at 36 hospitals in East Java Province. The result showed that approximately 25\% of patients in 36 hospitals who have been categorized as TB were actually non-TB, either presumptive or miss-classification of ICD-X. Continuous coordination is needed to maintain commitment, mobilizing resources, developing human capacity and monitoring evaluation implementation. TB case reported from active surveillance should be entry in SITT, however further discussion is needed relate to completeness of treatment outcome data.

\section{Conclusion}

Flow of TB case reporting from hospital done manually through entry data to SITT. Based on NTP reccomendation, CTB conducted an active surveillans covers 380 hospitals in 121 districts of CTB supported province. The study found that the proportion of missing cases in hospitals was $40 \%$, leaving $60 \%$ of cases had not been reported yet. Comparison of data showed that districts supported by CTB have a percentage of cases gap less than non CTB supported district. Other findings described proportion of TB missing case from public hospitals is $60 \%$, while for private hospitals is $40 \%$.

The challenges associated with hospital case report include the absence of integrated reporting in hospitals for TB cases reporting, and the provisions of collaboration among medical records and pulmonary unit. Integrated TB reporting should begin with an improvement of the Hospitals TB reporting system to make it as a routine role. Availability of technical guidelines as a guidance of personnel to withdrawn data from HIS furthermore export to SITT is one thing should be considered. Another important thing is the adequacy of human resources to reduce burden of hospital data staff.

Active surveillance shows suboptimal implementation of Directly Observed Treatment Short-course (DOTS) strategy and the need to strengthen hospital internal network. Standardized guideline adjusted with lesson learn from active surveillance of these phase and provisions of treatment outcome monitoring should be established to support active surveillance nationwide. The NTP needs also to collaborate with the 
Active Surveillance: Strategy to Reach the Unreported TB Patient in Hospitals

Directorate General of Health Services to establish a linkage between SIMRS and National TB surveillance system. 
Nenden Siti Aminah, Ratna Djuwita, Paulus Daniel Sahanggamu, Soelistyo, Helmi Suryani Nasution

\section{BIBLIOGRAPHY}

Dangisso, Mesay Hailu, Datiko, Daniel Gemechu, \& Lindtjørn, Bernt. (2014). Trends of tuberculosis case notification and treatment outcomes in the Sidama Zone, southern Ethiopia: ten-year retrospective trend analysis in urban-rural settings. PloS One, 9(12), e114225. Google Scholar

Danusantoso, H. (2000). Anamnesis Penyakit Paru. Buku Saku Ilmu Penyakit Paru, Hipokrates, Jakarta, 7-12. Google Scholar

Imas, Masturoh, \& Nauri, T. Anggita. (2018). Metodologi Penelitian Kesehatan Pusat [19] Pendidikan Sumber Daya Manusia Kesehatan. Badan Pengembangen [1] Pemberdayaan Sumber Daya Manusia Kesehatan. Google Scholar

Li, Tao, Shewade, Hemant Deepak, Soe, Kyaw Thu, Rainey, Jeanette J., Zhang, Hui, Du, Xin, \& Wang, Lixia. (2019). Under-reporting of diagnosed tuberculosis to the national surveillance system in China: an inventory study in nine counties in 2015. BMJ Open, 9(1), e021529. Google Scholar

Ministry of Health RI. (2017). "National TB Inventory Study in Indonesia," Ministry of Health RI, Central Jakarta, 2017. Google Scholar

Oliveira, Gisele Pinto de, Pinheiro, Rejane Sobrino, Coeli, Cláudia Medina, Barreira, Draurio, \& Codenotti, Stefano Barbosa. (2012). Mortality information system for identifying underreported cases of tuberculosis in Brazil. Revista Brasileira de Epidemiologia, 15, 468-477. Google Scholar

Organization, World Health. (2013). WHO report on the global tobacco epidemic, 2013: enforcing bans on tobacco advertising, promotion and sponsorship. World Health Organization. Google Scholar

Rahmadhani, Ika, Wijayanti, Rossalina Adi, \& Nuraini, Novita. (2020). Analisis Ketidaksesuaian Kode Diagnosis pada SIMRS dengan Berkas Klaim BPJS Klinik Obgyn. J-REMI: Jurnal Rekam Medik Dan Informasi Kesehatan, 1(4), 545-552. Google Scholar

Suvianto, Christa Adelia. (2020). Analysis of Factors Associated with the Healing Status of Pulmonary Tuberculosis Patients at Puskesmas Perumnas 1 Pontianak in 2018. Sriwijaya Journal of Medicine, 3(3), 32-41. Google Scholar

The Challenge TB. (2018a). “CTB Annually Report,” The Challenge TB, Central Jakarta, 2018. Google Scholar

The Challenge TB. (2018b). Technical Guideline of Active Surveillans, Central Jakarta: The Challenge TB, 2018. Google Scholar

Tola, Assefa, Minshore, Kirubel Minsamo, Ayele, Yohanes, \& Mekuria, Abraham Nigussie. (2019). Tuberculosis treatment outcomes and associated factors among TB patients attending public hospitals in Harar town, Eastern Ethiopia: a five-year retrospective study. Tuberculosis Research and Treatment, 2019. Google Scholar 
Uddin, Liliana, Wahyuni, Chatarina Umbul, \& Setiawan, Arif Yoni. (2021). Evaluasi Sistem Surveilans Tuberkulosis (TB) di Kabupaten Jember Berdasarkan Atribut Sistem Surveilans. Jurnal Kesehatan Global, 4(1), 41-53. Google Scholar

World Health Organization. (2018). Global Tuberculosis Report, Geneva: World Health Organization. Google Scholar

Zhou, Danju, Pender, Michelle, Jiang, Weixi, Mao, Wenhui, \& Tang, Shenglan. (2019). Under-reporting of TB cases and associated factors: a case study in China. BMC Public Health, 19(1), 1-9. Google Scholar

\section{Copyright holder:}

Nenden Siti Aminah, Ratna Djuwita, Paulus Daniel Sahanggamu, Soelistyo, Helmi Suryani Nasution (2021)

First publication right:

Journal Syntax Literate

This article is licensed under: 